Check for updates

Cite this: Chem. Commun., 2021, 57, 4110

Received 2nd March 2021, Accepted 1st April 2021

DOI: $10.1039 / \mathrm{d} 1 \mathrm{cc} 01149 a$

rsc.li/chemcomm

\section{Faster magic angle spinning reveals cellulose conformations in woods $\uparrow$}

\author{
Eric Chung-Yueh Yuan, ${ }^{a}$ Shing-Jong Huang, ${ }^{b}$ Hung-Chia Huang, ${ }^{a}$ Jari Sinkkonen, ${ }^{c}$ \\ Andres Oss, ${ }^{d}$ Mai-Liis Org, ${ }^{d}$ Ago Samoson, (D) *d Hwan-Ching Tai (D) *a and \\ Jerry Chun Chung Chan (D)*a
}

We present a first report on the detection of three different C6 conformers of cellulose in spruce, as revealed by solid-state ${ }^{1} \mathrm{H}-{ }^{13} \mathrm{C}$ correlation spectra. The breakthrough in ${ }^{1} \mathrm{H}$ resolution is achieved by magic-angle spinning in the regime of $150 \mathrm{kHz}$. The suppression of dense dipolar network of ${ }^{1} \mathrm{H}$ provides inverse detected ${ }^{13} \mathrm{C}$ spectra at a good sensitivity even in natural samples. We find that the glycosidic linkages are initially more ordered in spruce than maple, but a thermal treatment of spruce leads to a more heterogeneous packing order of the remaining cellulose fibrils.

${ }^{1} \mathrm{H}$ NMR spectroscopy is dominantly used in chemistry and biology if molecules and their complexes are undergoing rapid tumbling motion. Although a minor variation of chemical shift carries in principle a wealth of information on bond angles, overlap of the spectral lines in solid structures prevents comparably detailed analyses. Recent advances in magic-angle spinning (MAS) technology have triggered a variety of studies on pharmaceuticals, supramolecular structures, inorganicorganic hybrid materials, and biological solids. ${ }^{1,2}$ In addition, it has been shown that indirect detection of solid-state ${ }^{13} \mathrm{C}$ and ${ }^{15} \mathrm{~N}$ NMR could be achieved efficiently by ${ }^{1} \mathrm{H}$ MAS. ${ }^{3,4}$ Thanks to the further advances in precision machining and technical ceramics, the fastest magic-angle spinning frequency has increased from about 100 to $170 \mathrm{kHz}$ in a relatively short period of time..$^{5,6}$

Wood is one of the many important natural structures challenging the technical potential of NMR. It is arguably the most versatile organic material throughout human history. Nevertheless, our structural understanding of its underlying

\footnotetext{
${ }^{a}$ Department of Chemistry, National Taiwan University, Taipei 10617, Taiwan, Republic of China.E-mail: hctai@ntu.edu.tw, chanjcc@ntu.edu.tw

${ }^{b}$ Instrumentation Center, National Taiwan University, Taipei 10617, Taiwan, Republic of China

${ }^{c}$ Innovation Centre for Biomaterials, Stora Enso AB, Nacka 13154, Sweden

${ }^{d}$ Tallinn University of Technology, Estonia. E-mail: ago.samoson@yahoo.com

$\dagger$ Electronic supplementary information (ESI) available: Experimental procedures and details on analysis of samples and spectra. See DOI: 10.1039/d1cc01149a
}

cellulose polymers is rather limited. ${ }^{7}$ Although it has long been shown that ${ }^{13} \mathrm{C}$ solid-state NMR could provide important basic structural information on cellulose and wood samples, ${ }^{8-11}$ the molecular features associated with different types of wood remained largely elusive due to excessive line broadenings. Herein, we report that ${ }^{1} \mathrm{H}$ MAS could provide an opportunity to probe the structural features of spruce (a softwood, gymnosperm) and maple (a hardwood, angiosperm), providing better details in the atomic-molecular level. Thanks to the resolution achieved in the ${ }^{1} \mathrm{H}$ dimension, we were able to detect the three different C- 6 conformers of cellulose in spruce. Remarkably, a new category of NMR information inherently characteristic to disordered systems became amenable to analyses in solid structures.

In this work, the heteronuclear correlation (HETCOR) experiments, for which the pulse sequence is shown in Fig. S1 (ESI $\dagger$ ), were implemented using the technique of cross-polarization (CP). ${ }^{12}$ Fig. 1 shows the spectra acquired for spruce at a spinning frequency of 60 and $140 \mathrm{kHz}$ at two magnetic fields (9.4 and $18.8 \mathrm{~T}$ ). Schematic illustrations of the conformations of the glucose units are shown based on cellulose I $\beta$ crystal structure. ${ }^{13}$ The full spectrum is provided in Fig. S2 (ESI $\dagger$ ). At least five carbon signals can be distinguished and assigned, ${ }^{14,15}$ viz., C-4 of crystalline cellulose (CC), C-4 of amorphous cellulose (AC), C-2,3,5 of total cellulose (TC, AC plus CC), C- 1 of TC, and C- 6 of TC. ${ }^{16-18}$ The ${ }^{1} \mathrm{H}$ projections of the spectra were deconvoluted using DMFit-2019 ${ }^{19}$ and the extracted line widths at half maximum allow an assessment of the contribution of homogeneous line broadening (Fig. 2). In solid-state NMR, the signal broadening due to chemical shift distribution and homonuclear dipolar interactions belong to the categories of inhomogeneous and homogeneous broadenings, respectively. ${ }^{20}$ Although the ${ }^{1} \mathrm{H}$ NMR signals of spruce is to a large extent inhomogeneously broadened (Fig. S3, ESI $\dagger$ ), the results clearly indicated that high speed MAS remains effective in suppressing the homogeneous broadening, resulting in substantial improvement of resolution in ppm scale at higher field. This phenomenon is further corroborated by the results of 

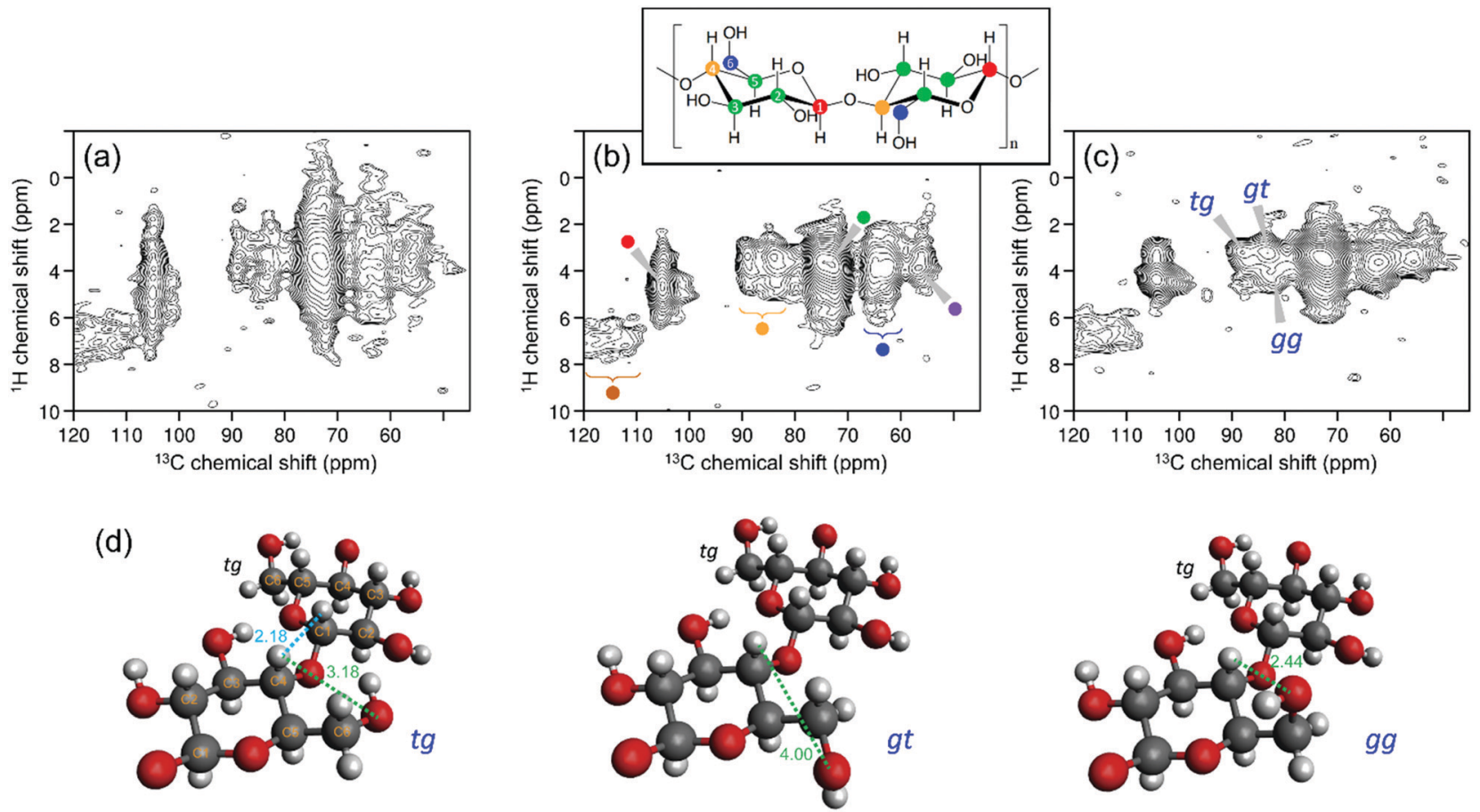

Fig. $1{ }^{1} \mathrm{H}\left\{{ }^{13} \mathrm{C}\right\}$ CP-HETCOR spectra of spruce acquired under different spinning frequencies and magnetic fields: (a) $60 \mathrm{kHz}, 9.4 \mathrm{~T}$ (400 $\mathrm{MHz}$; (b) $140 \mathrm{kHz}, 9.4 \mathrm{~T}$; (c) $140 \mathrm{kHz}, 18.8 \mathrm{~T}(800 \mathrm{MHz}$ ). Resolution in ppm scale is consitently enhanced by higher spinning frequency and magnetic field. The contour levels of all spectra were increased by a factor of 1.198 successively, where the base levels were set to $3 \times$ root-mean-square noise. The signals were assigned as C-1 (red), C-2,3,5 (green), C-4 (yellow), and C-6 (blue) of cellulose (inset). The signals of the methoxyl (purple) and aromatic groups (brown) were assigned to lignin. Tilting of the correlation peak of C- 6 at 62 ppm became apparent in (c). Schematic illustration of the conformations of the glucose units are shown in (d). Three conformers (tg, gt, gg) are illustrated for the nearer unit, whereas the one farther away is kept in the tg conformation. The distance between $\mathrm{C}-4(\mathrm{H})$ and $\mathrm{C}-6(\mathrm{OH})$ for the nearer unit is shown by the green dashed lines. The dashed line in cyan denotes the distance between the hydrogens of $\mathrm{C}-4$ and $\mathrm{C}-1$.

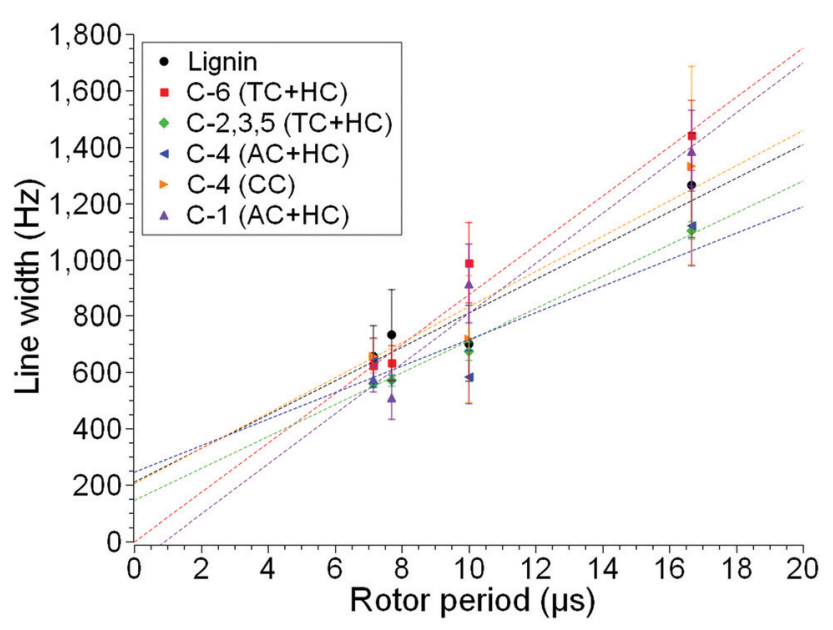

Fig. 2 Line widths at half maximum of the ${ }^{1} \mathrm{H}$ projections of ${ }^{1} \mathrm{H}\left\{{ }^{13} \mathrm{C}\right\}$ CP-HETCOR spectra acquired for spruce at a spinning frequency ranging from $60-150 \mathrm{kHz}$ at $9.4 \mathrm{~T}$. Extrapolation of the correlation lines to the $y$-axis gives an estimate for the upper bound of the residual homogeneous line width. HC: hemicellulose. AC/CC/TC: amorphous/crystalline/total cellulose. The linear dotted lines are the corresponding least-square fits.

glycine, which served as a model compound for very strongly interacting protons (Fig. S4, ESI $\dagger$ ). These and literature values gave $300 \mathrm{~Hz}$ as an upper bound to the residual homogeneous line widths at half maximum $\left(\Delta \nu_{1 / 2}\right)$ for various chemical environments in bioorganic structures like wood and cellulose. ${ }^{21}$ At higher magnetic fields this value should become too small to obscure the chemical shift variations of ${ }^{1} \mathrm{H}$ signal. As derived from Fig. 2, chemical shift distribution may contribute ca. $1 \mathrm{ppm}$ at the base of peaks at $18.8 \mathrm{~T}$, while residual homogeneous line broadening is less than $0.5 \mathrm{ppm}$, in a reasonable agreement with Fig. 1c. Detailed values are presented in Table S1 (ESI $\dagger$ ).

Many biofuel studies report uninformative broad lines in the ${ }^{13} \mathrm{C}$ spectra of biomass. ${ }^{8}$ Spectral lines are considered as a "dispersion", not amenable to any useful structural interpretation. An elegant method to obtain high-resolution ${ }^{13} \mathrm{C}$ and ${ }^{31} \mathrm{P}$ NMR spectra for disordered solids was developed by correlating the chemical shifts between homonuclear neighboring spins, ${ }^{22}$ from which the correlation ridges of $\mathrm{C} 2-\mathrm{C} 3$ and $\mathrm{C} 5-\mathrm{C} 6$ were ascribed to the structural variation of the cellulose II structures. ${ }^{23}$ We attempt to extend this principle to ubiquitous $\mathrm{C}-\mathrm{H}$ structural elements at a natural ${ }^{13} \mathrm{C}$ abundance. With the technical advance demonstrated in Fig. 1 and 2, the suppression of ${ }^{1} \mathrm{H}$ homogeneous line broadening by very fast MAS spinning made possible the correlation of chemical shift perturbations in both the ${ }^{1} \mathrm{H}$ and ${ }^{13} \mathrm{C}$ dimensions. Only in the highspeed-high-field spectrum of Fig. 1 we start to see a specific tilt of $2 \mathrm{D}$ ridges of the ${ }^{1} \mathrm{H}\left\{{ }^{13} \mathrm{C}\right\}$ CP-HETCOR signals. The same is 
(a)

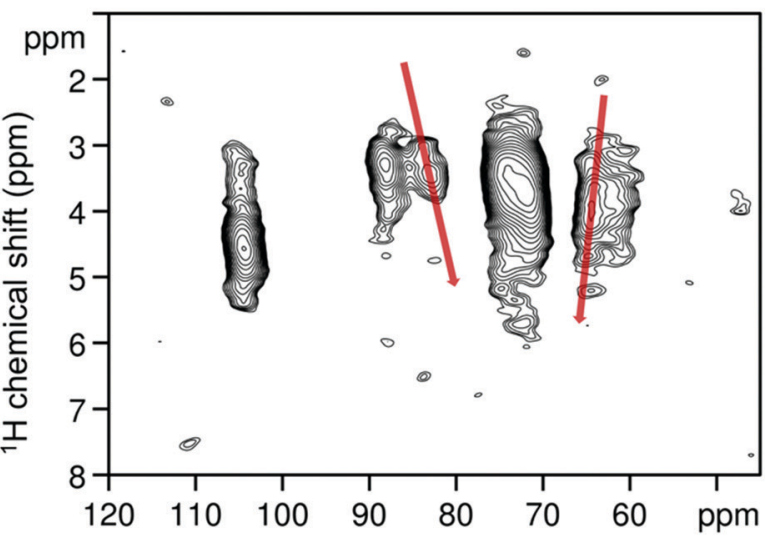

(b)

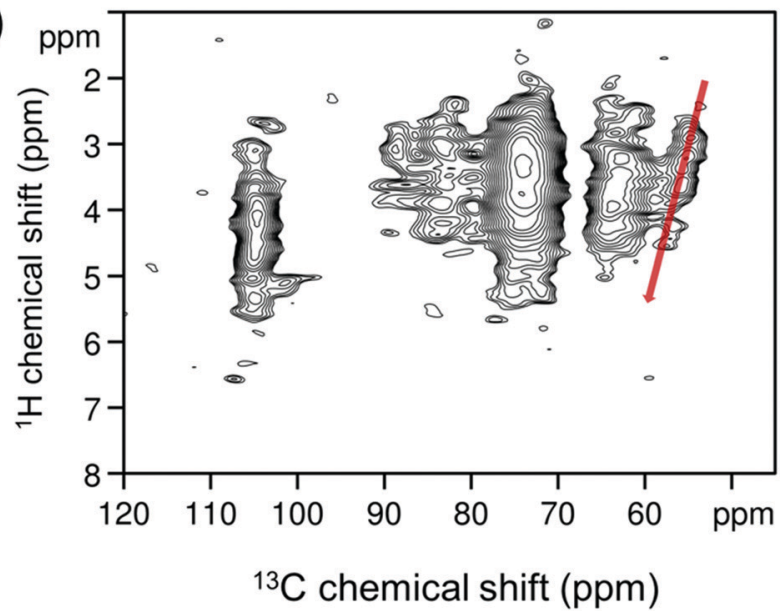

Fig. $3{ }^{1} \mathrm{H}\left\{{ }^{13} \mathrm{C}\right\}$ CP-HETCOR spectra acquired at $18.8 \mathrm{~T}$ under $150 \mathrm{kHz}$ spinning for (a) cotton cellulose and (b) maple. The correlation signals not running parallel to the vertical axis were highlighted by red arrows. The contour levels were set identically to Fig. 1.

observed in the spectra of cellulose and maple (Fig. 3). For the spectrum of cotton cellulose, the slopes of the elongated crosspeaks are positive for $\mathrm{C}-6\left(-\mathrm{CH}_{2}\right)$ but negative for $\mathrm{C}-4(-\mathrm{CH})$. The chemical shift variations of C-6 is caused by the rotation of the C-5/C-6 bond, resulting in tg, gt, and gg conformers (Fig. S5, ESI $\dagger){ }^{24}$ The positive slope of $\mathrm{C}-6\left(-\mathrm{CH}_{2}\right)$ suggests simultaneous deshielding or shielding in both the ${ }^{13} \mathrm{C}$ and ${ }^{1} \mathrm{H}$ dimensions, which is typically observed in most HETCOR spectra. ${ }^{25}$ The negative slopes of $\mathrm{C}-4(-\mathrm{CH})$ around $\delta\left({ }^{13} \mathrm{C}\right)$ of $84 \mathrm{ppm}$ in both cellulose and spruce are rather unexpected and particularly interesting.

The splitting of cellulose C-4 into 84 and 89 ppm peaks is the most striking feature in one-dimensional ${ }^{13} \mathrm{C}$ NMR of solid wood, but it remains poorly understood due to the lack of corresponding ${ }^{1} \mathrm{H}$ information. The $84 \mathrm{ppm}$ signal is usually assigned to $\mathrm{C}-4$ surface chains (amorphous or para-crystalline) in the cellulose elementary fibril, while the $89 \mathrm{ppm}$ signal is assigned to interior chains (crystalline). ${ }^{26,27}$ Recent quantum mechanical calculations have shown that C- 6 tg conformer contributes to the C-4 signal at $89 \mathrm{ppm},{ }^{28,29}$ but it remains unclear if the C-4 signal at $84 \mathrm{ppm}$ is dominated by gt or gg conformers. Our data offers a unique opportunity to examine
${ }^{13} \mathrm{C}-{ }^{1} \mathrm{H}$ correlations at $\mathrm{C}-4$ around $84 \mathrm{ppm}$ in intact spruce wood (Fig. 1c), ${ }^{11}$ which shows two correlation peaks at 3.4 (major) and 4.4 (minor) ppm in the ${ }^{1} \mathrm{H}$ dimension. The latter is likely associated with the gg conformer as -C6-O comes into close proximity of $-\mathrm{C} 4-\mathrm{H}$, causing a deshielding through hydrogen bonding. As such, the amorphous cellulose corresponding to the signal at $84 \mathrm{ppm}$ is primarily in the gt conformation. Oehme et al. predicted that $\delta(\mathrm{C} 4)$ is shifted in the shielded direction by 2-3 ppm going from gt to gg conformation, ${ }^{29}$ whereas Yang et al. predicted a larger shift of $5 \mathrm{ppm}^{28}$ Thus, the interconversion between gt and gg conformers may explain the intriguing negative slope observed in our spectra. The observed $\delta(\mathrm{C} 4)$ spectral shifts in spruce (Fig. 1c) and cellulose (Fig. 3a) are 1-2 ppm. The absence of 84/4.4 ppm correlation peak in cotton cellulose revealed its structural differences compared to spruce wood. Cotton cellulose has $\sim 48$ chains in its elementary fibril ${ }^{30}$ as opposed to 24 chains in spruce. ${ }^{31}$ The thicker fibrils and the lack of surrounding $\mathrm{HC}$ in cotton cellulose correlate with the relatively lower abundance of the gg conformer, rendering it more difficult to observe in our NMR spectrum. Recently, a very detailed solid-state NMR investigation of plant cell wall cellulose had been conducted by a ${ }^{13} \mathrm{C}$ NMR approach, ${ }^{32}$ where the relative population of tg, gt, and gg conformations were estimated by the signal build-up curves of the polarization transfer experiments. While this method had provided good insights into the structural arrangement of the studied cell walls, resolving $-\mathrm{C} 4-\mathrm{H}$ peaks as accomplished here is more straightforward in spectral analysis.

Heat treatment of spruce wood has been exploited in the timber industry to enhance their durability and stability. ${ }^{33-35}$ The ${ }^{1} \mathrm{H}\left\{{ }^{13} \mathrm{C}\right\}$ CP-HETCOR spectra were acquired for the spruce samples treated at $220^{\circ} \mathrm{C}$ for 1,2 , and $4 \mathrm{~h}$ in ambient air, and the samples are henceforth referred to as spruce- $1 \mathrm{~h}$, spruce- $2 \mathrm{~h}$, and spruce- $4 \mathrm{~h}$, respectively. The ${ }^{1} \mathrm{H}$ projections of the CP-HETCOR spectra of cellulose, maple and spruce at various levels of heat treatment were deconvoluted (Fig. S6, ESI $\dagger$ ) and the results are summarized in Tables S1 and S2 (ESI $\dagger$ ). As shown in Fig. 4, the ${ }^{1} \mathrm{H}$ line widths for the cellulose of spruce and spruce- $1 \mathrm{~h}$ were very similar to those of microcrystalline cellulose. On the other hand, the ${ }^{1} \mathrm{H}$ signals for maple had, in general, larger line widths. This phenomenon is particularly prominent for C-1 and C-4 (Fig. 4). In other words, the packing of cellulose fibrils is more ordered in spruce (a softwood) than maple (a hardwood). The former shows a higher degree of crystallinity, as judged by its more prominent CC signal intensity at $89 \mathrm{ppm}$ in the ${ }^{13} \mathrm{C}\left\{{ }^{1} \mathrm{H}\right\}$ CPMAS spectra (Fig. S7, ESI $\dagger$ ). ${ }^{26,27}$ The spruce is known to be a wood with very straight grains and extremely fast sound transmission speed in the longitudinal direction. Therefore, spruce is used for the soundboard of many musical instruments including violins, cellos, guitars, and pianos. ${ }^{36}$ Our data confirm that spruce has a greater molecular packing order than maple with respect to cellulose chains. Moreover, the effect of thermal treatment was best manifested in the $\Delta \nu_{1 / 2}$ data for spruce- $4 \mathrm{~h}$, which exhibited a significant increase. Thus, we concluded that a thermal 


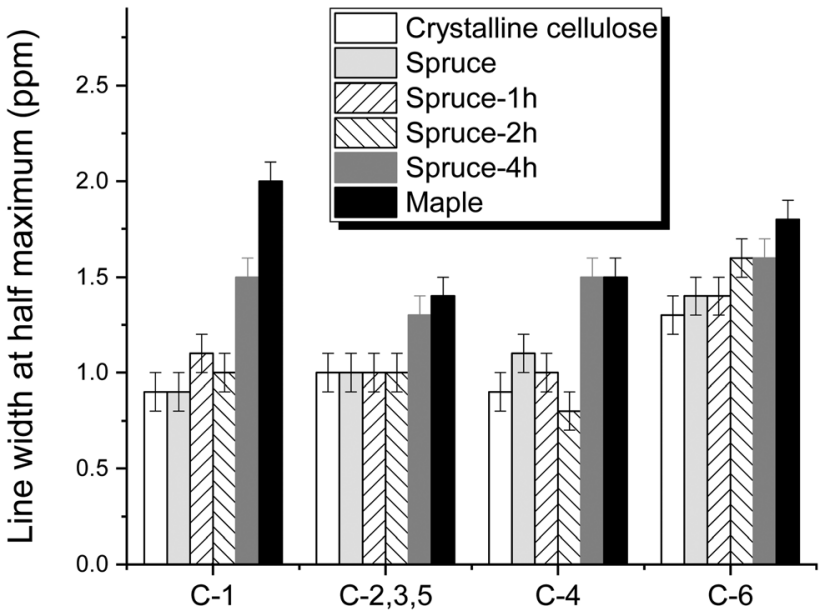

Fig. 4 Comparison of the ${ }^{1} \mathrm{H}$ signal line widths of cotton microcrystalline cellulose and the cellulose in spruce, heat-treated spruce, and maple.

treatment for a sufficiently long period of time would impart structural heterogeneity. It has been reported that thermally treated wood undergoes HC decomposition and lignin cleavage/ recondensation..$^{35,37,38}$ Heating spruce at $220{ }^{\circ} \mathrm{C}$ under ambient atmosphere causes continuous mass loss observed by thermogravimetric analysis over the course of $4 \mathrm{~h}$ (Fig. S8, ESI $\dagger$ ). The first stage of mass loss is due to moisture loss, followed by $\mathrm{HC}$ fragmentation due to hydrolysis and oxidation, with some saccharides being converted into volatile organic compounds. ${ }^{35,37}$ The consequence of HC breakdown is the creation of free space and rearrangement of remaining fibers, which may result in a more heterogeneous packing order of $\mathrm{HC}$ and cellulose chains.

In summary, the two-dimensional NMR technique of ${ }^{1} \mathrm{H}\left\{{ }^{13} \mathrm{C}\right\}$ CP-HETCOR under very fast MAS conditions is able to detect various conformers of glucose units in wood as well as cellulose structural variations between softwood and hardwood. It also revealed that the structural changes in thermally treated wood might be correlated to increased heterogeneity of fibril packing and HC decomposition. This effective resolution enhancement in ${ }^{1} \mathrm{H}$ NMR can be generally helpful for analyses of low-order systems and may be extended to various types of other polymers.

This work was financially supported by the Ministry of Science and Technology (107-2113-M-002-004 and 108-2628-M002-012-MY3). The NMR measurements were carried out at the Instrumentation Center of National Taiwan University, supported by the Ministry of Science and Technology. MLO, AO and AS were supported by ETAg project PUT1534, NMR Instituut MTÜ and Darklands OÜ.

\section{Conflicts of interest}

There are no conflicts to declare.

\section{References}

1 S. P. Brown, Solid State Nucl. Magn. Reson., 2012, 41, 1-27.
2 R. Zhang, K. H. Mroue and A. Ramamoorthy, Acc. Chem. Res., 2017, 50, 1105-1113.

3 Y. Ishii and R. Tycko, J. Magn. Reson., 2000, 142, 199-204.

4 Y. Ishii, J. P. Yesinowski and R. Tycko, J. Am. Chem. Soc., 2001, 123, 2921-2922.

5 M. Deschamps, in Annual Reports on NMR Spectroscopy, ed. G. A. Webb, Academic Press, 2014, vol. 81, pp. 109-144.

6 A. Samoson, J. Magn. Reson., 2019, 306, 167-172.

7 R. M. Rowell, Handbook of Wood Chemistry and Wood Composites, CRC Press, Boca Raton, 2nd edn, 2012.

8 M. Foston, Curr. Opin. Biotechnol., 2014, 27, 176-184.

9 R. Dupree, T. J. Simmons, J. C. Mortimer, D. Patel, D. Iuga, S. P. Brown and P. Dupree, Biochemistry, 2015, 54, 2335-2345.

10 O. M. Terrett, J. J. Lyczakowski, L. Yu, D. Iuga, W. T. Franks, S. P. Brown, R. Dupree and P. Dupree, Nat. Commun., 2019, 10, 1-11.

11 X. Kang, A. Kirui, M. C. Dickwella Widanage, F. Mentink-Vigier, D. J. Cosgrove and T. Wang, Nat. Commun., 2019, 10, 347.

12 B. Meier, Chem. Phys. Lett., 1992, 188, 201-207.

13 Y. Nishiyama, P. Langan and H. Chanzy, J. Am. Chem. Soc., 2002, 124, 9074-9082.

14 A. Isogai, M. Usuda, T. Kato, T. Uryu and R. H. Atalla, Macromolecules, 1989, 22, 3168-3172.

15 H. Kono, S. Yunoki, T. Shikano, M. Fujiwara, T. Erata and M. Takai, J. Am. Chem. Soc., 2002, 124, 7506-7511.

16 M. Bardet, D. Gagnaire, R. Nardin, D. Robert and M. Vincendon, Holzforschung, 1986, 40, 17-24.

17 A. M. Gil and C. P. Neto, in Annual Reports on Nmr Spectroscopy, ed. G. A. Webb, Elsevier Academic Press Inc, San Diego, 1999, vol. 37, pp. $75-117$.

18 H.-C. Tai, G.-C. Li, S.-J. Huang, C.-R. Jhu, J.-H. Chung, B. Y. Wang, C.-S. Hsu, B. Brandmair, D.-T. Chung, H. M. Chen and J. C. C. Chan, Proc. Natl. Acad. Sci. U. S. A., 2017, 114, 27-32.

19 D. Massiot, F. Fayon, M. Capron, I. King, S. Le Calve, B. Alonso, J. O. Durand, B. Bujoli, Z. H. Gan and G. Hoatson, Magn. Reson. Chem., 2002, 40, 70-76.

20 M. Maricq and J. Waugh, J. Chem. Phys., 1979, 70, 3300-3316.

21 S. Penzel, A. Oss, M.-L. Org, A. Samoson, A. Böckmann, M. Ernst and B. H. Meier, J. Biomol. NMR, 2019, 73, 19-29.

22 D. Sakellariou, S. P. Brown, A. Lesage, S. Hediger, M. Bardet, C. A. Meriles, A. Pines and L. Emsley, J. Am. Chem. Soc., 2003, 125, $4376-4380$

23 S. Cadars, A. Lesage and L. Emsley, J. Am. Chem. Soc., 2005, 127, 4466-4476.

24 F. Horii, A. Hirai and R. Kitamaru, Polym. Bull., 1983, 10, 357-361.

25 M. P. Hanrahan, A. Venkatesh, S. L. Carnahan, J. L. Calahan, J. W. Lubach, E. J. Munson and A. J. Rossini, Phys. Chem. Chem. Phys., 2017, 19, 28153-28162.

26 R. J. Viëtor, R. H. Newman, M.-A. Ha, D. C. Apperley and M. C. Jarvis, Plant J., 2002, 30, 721-731.

27 T. Wang, H. Yang, J. D. Kubicki and M. Hong, Biomacromolecules, 2016, 17, 2210-2222.

28 H. Yang, T. Wang, D. Oehme, L. Petridis, M. Hong and J. D. Kubicki, Cellulose, 2018, 25, 23-36.

29 D. P. Oehme, H. Yang and J. D. Kubicki, Cellulose, 2018, 25, 3755-3777.

30 M. MartÃ-nez-Sanz, F. Pettolino, B. Flanagan, M. J. Gidley and E. P. Gilbert, Carbohydr. Polym., 2017, 175, 450-463.

31 A. N. Fernandes, L. H. Thomas, C. M. Altaner, P. Callow, V. T. Forsyth, D. C. Apperley, C. J. Kennedy and M. C. Jarvis, Proc. Natl. Acad. Sci. U. S. A., 2011, 108, 18863-18864.

32 P. Phyo, T. Wang, Y. Yang, H. O'Neill and M. Hong, Biomacromolecules, 2018, 19, 1485-1497.

33 B. F. Tjeerdsma, M. Boonstra, A. Pizzi, P. Tekely and H. Militz, Holz Roh-Werkst., 1998, 56, 149-153.

34 S. Metsä-Kortelainen, T. Antikainen and P. Viitaniemi, Holz Als RohWerkst, 2006, 64, 192-197.

35 B. Esteves and H. Pereira, BioResources, 2009, 4, 370-404.

36 V. Bucur, Handbook of Materials for String Musical Instruments, Springer International Publishing, 2016.

37 S. Yildiz, E. D. Gezer and U. C. Yildiz, Build. Environ., 2006, 41, $1762-1766$.

38 M. M. González-Peña, S. F. Curling and M. D. C. Hale, Polym. Degrad. Stab., 2009, 94, 2184-2193. 